\title{
Soil Pollution by the Cement Industry in the Bazian Vicinity, Kurdistan Region
}

Saima Jadoon ${ }^{1 *}$, Abdulfattah Ahmad Amin², Arif Malik ${ }^{3}$ and Hamza Kamal ${ }^{1 *}$

${ }^{1}$ Department of Natural Resources Engineering and Management, University of Kurdistan Hewlêr, Erbil, Iraq

${ }^{2}$ Erbil Technology Institute, Erbil Polytechnic University, Erbil, Kurdistan, Iraq

${ }^{3}$ Institute of Molecular Biology and Biotechnology, University of Lahore, Lahore, Pakistan

\begin{abstract}
The three most significant things in our life are air, water, and soil which are essential for life and any imbalance of these three cause a big problem in nature. Soil is one of the most common agents in life and supplies us with all the basic necessities. Portland cement is one of the common types of cement which is used in construction nowadays. But soil can be polluted by cement plants, where cement industries are established. The chemical composition of cement is a mixture of calcium aluminum silicate also, a trace amount of $\mathrm{Cd}, \mathrm{Pb}, \mathrm{Fe}, \mathrm{Ti}$ and silica. According to several chemical analyses the area surrounding industries show that the further the area is from the factory, the better as soil pollution decreases. In this research paper, we checked the physiochemical $\mathrm{pH}$, electrical conductivity, nitrate ions, sulphate ions, Lead ions and calcium ions content in soil in the Bazian area. The area is far from the surrounding industries and this shows that the further the area is from the factory, the better as soil pollution decreases. There is positive correlation between the calcium ions and electrical conductivity. There is negative correlation between $\mathrm{pH}$ and concentration of lead ions. There is also weak correlation between sulphate and nitrate ions concentrations in soil samples.
\end{abstract}

Keywords: Soil pollution; Bazian; Physicochemical parameters

\section{Introduction}

Cement is the most common material that is used in wide range of construction applications nowadays, such as pavement, houses, offices, roads, bridges and water supply system such as dams and cement is the main part in concrete. It becomes hard when it is mixed with water [1-7]. There are two common types of cement hydraulic and non- hydraulic which are based on the ability of the cement that can be hardened or set by the chemical interaction with water, Portland cement is one of the extensively used types of cement and it is the hydraulic sort that means it can be hardened under water. The chemical composition of Portland cement consists of lime (calcium oxide, $\mathrm{CaO}$ ) mixed with silica (silicon dioxide, $\mathrm{SiO}_{2}$ ), usually containing calcium sulfate $\left(\mathrm{CaSO}_{4}\right)$ and alumina (aluminum oxide, $\left.\mathrm{Al}_{2} \mathrm{O}_{3}\right)$ [8,9]. The top three countries for producing cement, in particular Portland cement are, China, India and the USA. Between 2005 to 2010 China to produce 2,480 million tons of cement per year. Because of most fast developing building construction and population growth in most countries and especially in Kurdistan where there are a lot of mountains with a wide range of limestone that is suitable for producing cement, demand on cement industry year after year will be more. Therefore, a lot of cement industries come to Kurdistan to establish factories and to provide cement for the foundations and structures of the buildings which we live and work in. Cement plants have been named the 17 most pollutant industries by the central control board. For instance, Bazian cement plant established since 2008 in Kurdistan located about 30 kilometers away from Sulaimanyah, is able to produce is about 2.5 million tons per year. With certainty, all cement factories to some extent has cause environmental pollution. The most important point of view is that we must be concerned with the environment and at least, we would be able to reduce the rate of pollution by the cement industry. The three major types of environmental pollution by cement the industry are air, water and soil pollution which are dangerous for human health. Cement industry releases carbon dioxide into air directly by the heating of limestone, as well as the blasting in quarries causes of dust and pollutes air. The likewise, water can be polluted by the cement industry by the way of throwing their waste into the water system and this will lead to increased alkalinity levels of the water as high as $12 \mathrm{pH}$ Soil composition made up 45 percent of mineral, 25 percent of air, 25 percent of water and only 5 percent of organic matter, therefore soil can be polluted by the Cement industry by exchanging their properties such as increasing levels of the toxic substances in soil, and a change in $\mathrm{pH}, \mathrm{K}, \mathrm{Ca}, \mathrm{Mg}$, and soil organic matter. This research paper will focus on soil pollution due to the cement plants $[10,11]$.

\section{Methodology}

For the determination of the physiochemical properties of the contaminated soil samples 600 model Plaintest micro was used to determine the $\mathrm{pH}$, TDS, and electric conductivity respectively (600 modle Plaintest micro, UK). In addition, for the determination of the anions concentration Sulphate and Nitrate in the contaminated water samples, UV/Visible Spectrophotometer was employed (modle 6705 UV/Vis Jenway, UK). While, for the Cations concentration which are $\left(\mathrm{Ca}^{+2}, \mathrm{~Pb}^{+2}\right)$, instrumental techniques were employed to determine the concentrations. These instruments are respectively flame photometer for calcium determination (Model PFP7 Jenway, UK), and Atomic absorption spectrophotometer for Lead Concentration (Model 210/211/ Buck Scientific) [12-21].

\section{Results and Discussion}

\section{Results}

The parameters in control soil like electrical conductivity, $\mathrm{pH}$, lead

*Corresponding authors: Saima Jadoon, Department of Natural Resources Engineering and Management, University of Kurdistan Hewlêr, Erbil, Iraq, Tel: +009647510307184; E-mail: saima.jadoon95@gmail.com

Hamza Kamal, Department of Natural Resources Engineering and Management, University of Kurdistan Hewlêr, Erbil, Iraq, E-mail: h.kamal1@ukh.edu.krd

Received July 11, 2016; Accepted October 17, 2016; Published October 24, 2016

Citation: Jadoon S, Amin AA, Malik A, Kamal H (2016) Soil Pollution by the Cement Industry in the Bazian Vicinity, Kurdistan Region. J Environ Anal Toxicol 6: 413. doi: 10.4172/2161-0525.1000413

Copyright: @ 2016 Jadoon S, et al. This is an open-access article distributed under the terms of the Creative Commons Attribution License, which permits unrestricted use, distribution, and reproduction in any medium, provided the original author and source are credited. 
Citation: Jadoon S, Amin AA, Malik A, Kamal H (2016) Soil Pollution by the Cement Industry in the Bazian Vicinity, Kurdistan Region. J Environ Anal Toxicol 6: 413. doi: 10.4172/2161-0525.1000413

Page 2 of 3

ions, sulphate ions, nitrate ions were found normal as per standard of WHO.

The above table shows that the value of the calcium range is 28 $44 \mathrm{ppm}$. The standard saturation of the calcium range in soil which is acceptable by agronomists is 25-37.5 ppm. Thus, most of the result of soil samples are not suitable for growth of plants except for two of them which are $28 \mathrm{ppm}$ and $34 \mathrm{ppm}$. These two samples are suitable for the plants roots to grow (Tables 1-3).

The range of electrical conductivity value is $97.2-487 \mu \mathrm{S} / \mathrm{cm}$ and the standard value of electrical conductivity should be between 0 to 100000 $\mu \mathrm{S} / \mathrm{cm}$ for good soil. Thus, the result show that the soil samples around that area are suitable for the growth of plants.

The value of $\mathrm{pH}$ level is 7.14-8.1 in the soil and the suitable value of soil $\mathrm{pH}$ to growth the root of plant fall within a range between 6.5 which is slightly acidic and 7.5 which is slightly alkaline. The results show that most of the $\mathrm{pH}$ values of soil samples are not suitable for root growth of plants except for samples 4 and 5 which have values of 7.14 and 7.42.

The value of the nitrate range is $0.8-2.3 \mathrm{ppm}$ and the fertility level of nitrates in a soil should not less than $10 \mathrm{ppm}$, otherwise the soil will count as a low fertility level and not suitable for plant grow.

The sulphate value range is $1.625-15.8 \mathrm{ppm}$, and we can determine the level of sulphate in the soil according to this standard if $<4$ is very low, 4 to 10 is low, and 10 to 20 is medium. Thus, the result show that the level of sulphate is very low in sample 6 and low in sample 3 and 5 . It is medium in sample 1,2 and 4 . This shows some areas are suitable for agriculture and some are not.

The lead value range is $0.8-1.57 \mathrm{ppm}$, and according to the standard level of lead in the soil, the value of lead is low because it is less than 22 $\mathrm{ppm}$. The result of soil samples show that the level of lead in the area of the study is too low and the soil is not polluted by lead.

The above table shows that the value of calcium range is $16-47 \mathrm{ppm}$. The standard saturation of calcium range in soil which is acceptable by agronomists is $25-37.5 \mathrm{ppm}$. Thus, the result of three soil samples are not suitable for growth of the plants but, the other three samples are suitable for plant roots to grow.

The range of electrical conductivity value is $53.7-571 \mu \mathrm{S} / \mathrm{cm}$ and the standard value of electrical conductivity should be between 0 to 100000

\begin{tabular}{|c|c|c|c|c|c|c|}
\hline Sample No & Calcium ions (ppm) & $\begin{array}{l}\text { Electrical conductivity } \\
\qquad(\mu \mathrm{S} / \mathrm{cm})\end{array}$ & $\mathrm{pH}$ & Lead ions (ppm) & Sulphate ions (ppm) & Nitrate ions (ppm) \\
\hline 1 & 28 & 97.2 & 7.91 & 0.013 & 0.09 & 0.44 \\
\hline 2 & 44 & 487 & 7.72 & 0.013 & 0.08 & 0.608 \\
\hline 3 & 41 & 285 & 8.1 & 0.016 & 0.071 & 0.566 \\
\hline 4 & 32 & 351 & 7.42 & 0.019 & 0.114 & 1.406 \\
\hline 5 & 34 & 270 & 7.14 & 0.02 & 0.068 & 1.227 \\
\hline 6 & 38 & 77.3 & 7.78 & 0.011 & 0.01 & 1.176 \\
\hline
\end{tabular}

Table 1: This table shows the value of physicochemical parameters in soil samples below $30 \mathrm{~cm}$.

\begin{tabular}{|c|c|c|c|c|c|c|}
\hline Sample No & Calcium ions (ppm) & $\begin{array}{l}\text { Electrical conductivity } \\
(\mu \mathrm{S} / \mathrm{cm})\end{array}$ & pH & Lead ions (ppm) & Sulphate ions (ppm) & Nitrate ions (ppm) \\
\hline 1 & 16 & 53.7 & 7.61 & 0.018 & 0.116 & 0.672 \\
\hline 2 & 47 & 571 & 7.21 & 0.011 & 0.081 & 0.527 \\
\hline 3 & 42 & 446 & 7.82 & 0.012 & 0.07 & 0.638 \\
\hline 4 & 38 & 326 & 7.06 & 0.016 & 0.092 & 0.65 \\
\hline 5 & 28 & 351 & 7.76 & 0.021 & 0.945 & 1.062 \\
\hline 6 & 25 & 88.9 & 7.6 & 0.02 & 0.865 & 1.22 \\
\hline
\end{tabular}

Table 2: This table shows the value of physicochemical parameters from the soil surface.

$\mu \mathrm{S} / \mathrm{cm}$ for good soil. Thus, the results show that the soil samples around

The value of $\mathrm{pH}$ level is 7.06-7.82 in the soil and the suitable value of soil $\mathrm{pH}$ to grow the roots of plants falls within a range between 6.5 which is slightly acidic and 7.5 which is slightly alkaline. The results most of the $\mathrm{pH}$ values of soil samples are not suitable for the root growth of plant except for samples 2 and 4 which have values of 7.21 and 7.06 .

The value of nitrate range is 1.01-2.0 ppm and the fertility level of nitrates in soil should not be less than $10 \mathrm{ppm}$, otherwise the soil will

level of sulphate in soil according to this standard if $<4$ is very low 0.4 to 10 is low, 10 to 20 is medium. 20 to 50 is high and $>50$ is very high. Thus, the result shows that the level of sulphate is low in sample 3 , medium in sample 1,2,4 and very high in sample 5 and 6 . This shows some areas are suitable for agriculture and some are not.

The range of lead is $0.86-1.6 \mathrm{ppm}$, according to the standard level of lead in soil, the value of lead will be low if it is less than $22 \mathrm{ppm}$. The result of soil samples show that the level of lead in the area of study is too low and the soil is not polluted by lead.

\section{Discussion}

In the above table, there is a positive correlation between calcium and electrical conductivity. It means by increasing the concentration of calcium the electrical conductivity of soil samples increased. There is a negative correlation between $\mathrm{pH}$ and the concentration of lead and it means a high value of $\mathrm{pH}$, and a low concentration of lead. There is also weak correlation between sulphate and nitrate ions concentrations of soil samples.

\section{Conclusion}

This study shows that the soil of the studied area could be categorized as moderately to heavily polluted. The value of different parameter in soil samples below $30 \mathrm{~cm}$, showed the $\mathrm{pH}$ and electrical conductivity values are suitable for growth. Where the concentration of calcium is not suitable for plant growth. The result of nitrate and sulphate in soil samples showed the clearly low concentration of nitrate content in the soil of the polluted area and this low concentration is not 
Citation: Jadoon S, Amin AA, Malik A, Kamal H (2016) Soil Pollution by the Cement Industry in the Bazian Vicinity, Kurdistan Region. J Environ Anal Toxicol 6: 413. doi: 10.4172/2161-0525.1000413

Page 3 of 3

\begin{tabular}{|c|c|c|c|c|c|c|}
\hline & Calcium ions (ppm) & $\begin{array}{c}\text { Electrical } \\
\text { conductivity }(\mu \mathrm{S} / \mathrm{cm})\end{array}$ & pH & Lead ions (ppm) & Sulphate ions (ppm) & Nitrate ions (ppm) \\
\hline Calcium ions (ppm) & 1 & & & & & \\
\hline $\begin{array}{c}\text { Electrical } \\
\text { conductivity }(\mu \mathrm{S} / \mathrm{cm})\end{array}$ & -0.675744974 & 1 & & & & \\
\hline $\mathrm{pH}$ & -0.085843662 & -0.269904549 & 1 & & & \\
\hline Lead ions (ppm) & -0.556038736 & -0.261366287 & -0.20210349 & 1 & & \\
\hline Sulphate ions (ppm) & -0.251257498 & -0.144319226 & 0.10831429 & 0.618944569 & 1 & \\
\hline Nitrate ions (ppm) & -0.193228903 & -0.248609195 & -0.242663108 & 0.583771106 & 0.379651695 & 1 \\
\hline
\end{tabular}

Table 3: This table represents correlation between physicochemical parameters of soil surface samples and below the $30 \mathrm{~cm}$ soil samples.

adequate to plant growth. The analytical results of nitrate and sulphate concentration level showed that in some areas the ratio of sulphate and nitrate are adequate for the growth of plant but not in the other. The value of physicochemical parameters from the soil surface. Like the concentration of calcium is acceptable in three samples out of six samples. Where the value of electrical conductivity is suitable for, the growth of plants. The $\mathrm{pH}$ values are not suitable for plant growth. The concentration of nitrate is suitable for plant growth where the value of sulphate is not suitable for plant growth. The value of lead is very low and it does not effect the properties of the soil samples. There is a positive correlation between calcium and electrical conductivity. According to several chemical analyses the area surrounding industries shows that the further the area is from the factories, the better the soil pollution decreases. There is negative correlation between $\mathrm{pH}$ and concentration of lead. There is also a weak correlation between sulphate and nitrate ion concentrations in soil samples.

\section{Recommendation}

We recommend first, reduce land disturbance by blasting operations in quarry area that has been done by cement plants prevent run off and leave a lot of vegetation cover. Second, cement plants should control the dust by fine water sprays. Third for all vehicle and big machine engines should use low sulphur diesel oil. Forth, the plant should cover of building materials like cement and put them in a place where they will not be washed into waterways or drainage areas.

\section{References}

1. Al-Khashman O, Shawabkeh R (2006) Metals distribution in soils around the cement factory in southern Jordan. Environmental Pollution 140: 387-394.

2. Lacatusu R, Dumitru M, Risnoveanu I, Ciobanu C, Lungu M, et al. (2001) Soil pollution by acid rains and heavy metals in Zlatna region, Romania. Sustaining the global farm. Purdue University, West Lafayette, pp: 817-820.

3. Ben Mussa SA, Elferjani HS, Haroun FA, Abdelnabi FF (2009) Determination of Available Nitrate, Phosphate and Sulfate in Soil Samples. International Journal of PharmTech Research 1: 598-604.

4. Blakemore L (2016) pp: 1-3 (Online).

5. Hill Laboratories (1987) Available at: http://www.hill-laboratories.com/

6. Buchholz DD, Brown JR, Garret JD, Hanson RG, Wheaton HN (2004) Soil test interpretations and recommendations handbook. University of MissouriCollege of Agriculture, Division of Plant Sciences, pp: 1-39.

7. Charef A, Ayed L, Azzouzi R (2011) Irrigation water qualities-soil pollution (heavy metals and salinity) in mornag irrigated perimeter (SW Tunis, North Tunisia). In: Fifteenth International Water Technology Conference, IWTC-15, Alexandria, Egypt.

8. Chaurasia S, Karwariya A, Dev Gupta A (2013) Effect of cement industry pollution on chlorophyll content of some crops at Kodinar, Gujarat, India. Proceedings of the International Academy of Ecology and Environmental Sciences 3: 288-295.

9. Iqbal MZ, Shafiq M (2000) Periodical effect of cement dust pollution on the growth of some plant species. Turkish Journal of Botany 25: 19-24.
10. Jain R, Jain PL (2006) Pollution of Soil Due to Cement Factory Near Narsingarh Madhya Pradesh (India). Journal of Environmental Research and Development 1: 151-154.

11. Al-Omran AM, El-Maghraby E, Nadeem EA, Ali M, Al-Qahtani SM (2011) Impact of cement dust on some soil properties around the cement factory in Al-Hasa oasis, Saudi Arabia. Am Eurasian J Agric Environ Sc 11: 840-846.

12. Ogunkunle CO, Fatoba PO (2013) Pollution loads and the ecological risk assessment of soil heavy metals around a mega cement factory in southwest Nigeria. Polish Journal of Environmental Studies 22: 487-493.

13. Pawar DR, Randhe DB, Shaikh M (2009) Laboratory Testing Procedure for Soil \& Water Sample Analysis. Water Resources Department Directorate of Irrigation Research \& Development, Pune, India, pp: 1-128.

14. García R, Báez AP (2012) Atomic Absorption Spectrometry (AAS). INTECH Open Access Publisher, Rijeka, Croatia - European Union.

15. Shivaram S (2014) Measures to Contain Pollution Caused Due to Cement Production. International Journal of Emerging Technology and Advanced Engineering 4: 135-140.

16. Suciu I, Cosma C, Todică M, Bolboacă SD, Jäntschi L (2008) Analysis of Soil Heavy Metal Pollution and Pattern in Central Transylvania. International Journal of Molecular Sciences 9: 434-453.

17. Namasivayam C (1994) Conditioning of the soil polluted by cement dust using polymer flocculants: 1 . Effects of anionic polyacrylamide. Toxicological \& Environmental Chemistry 42: 65-70.

18. Van Reeuwijk LP (2002) Procedures for Soil Analysis. 6th edn. Netherlands: International Soil Reference and Information Center.

19. Williams PJ (2010) Pollution Control Technology for the Cement Industry Montego Bay, Jamaica: Babcock \& Wilcox Power Generation Group, Inc. Barberton, Ohio, USA

20. Tavallali H, Asrari E, Attaran AM, Tabandeh M (2010) Sensitive determination of lead in soil and water samples by cloud point extraction-flame atomic absorption spectrometry method. Int J ChemTech Res 2: 1731-1737.

21. http://www.esciencecentral.org/journals/pollution-and-effects.php 